G557(P) INTRODUCTION OF CARE BUNDLE FOR NON-INVASIVE RESPIRATORY SUPPORT FOR NEONATES ADMITTED TO A TERTIARY NEONATAL UNIT IN THE UNITED KINGDOM: A QUALITY IMPROVEMENT PROJECT

KA Evans, S Shetty, T Sigola-Rowett, A Kulkani. Neonatology, St George's University Hospitals NHS FT, London, UK

10.1136/archdischild-2020-rcpch.475

Aims It is widely recognised in neonatal practice that there is variation in the instigation, switching and weaning of infants between various forms of non-invasive ventilation. With continuous positive airway pressure (CPAP) circuits lasting seven days and high flow, high temperature, humidified nasal cannula oxygen (HFNCO2) circuits lasting thirty days there is a clear financial incentive to minimise circuits used. Introduction of care bundle to standardise initiation and switching of non-invasive respiratory support in babies needing respiratory support will lead to reduction of respiratory circuits being used for non-invasive support, making its use more efficient.

Methods Pre-intervention data was analysing using Badger data from all babies born in 2016 looking at the number of CPAP and HFNCO2 circuits utilised. A comprehensive teaching package was introduced to the nursing and medical teams around circuit usage and costs ( $£ 93$ per CPAP circuit and $£ 101$ per HFNCO2 circuit). Specific guidelines were developed to guide initiation, switching and weaning of respiratory support. Post-intervention data was collected from all babies born in 2017 for comparison.

Results There was decreased use of CPAP and HFNCO2 circuits in babies requiring respiratory support. Regarding CPAP there was a reduction from 1.53 circuits per baby to 1.0 and with HFNCO2 this was 0.64 circuit per baby to 0.49 . In lower gestational ages this was more significant; under 28 weeks gestation it went from 2.44 to 1.59 circuits per baby with CPAP and 1.02 to 0.58 circuits per baby with HFNCO2. This equates to a gross yearly saving of $£ 22,800$ (assuming a similar patient population with 3000 annual admissions).

Conclusion Introduction of a care bundle involving an education package, clear written guidelines and increased awareness of durations and costs of CPAP and HFNCO2 circuits amongst medical and nursing staff leads to considerable cost savings when incorporated into clinical practice.

\section{G558(P) REVIEW OF NEONATAL CORTISOL EVALUATION BETWEEN 2012-2018 IN A SINGLE CENTRE: TRENDS, OUTCOMES AND ASSOCIATIONS}

${ }^{1} \mathrm{~S}$ Sarvasiddhi, ${ }^{2} \mathrm{E}$ Von Boxel, ${ }^{3} \mathrm{~S}$ Menon, ${ }^{4} \mathrm{~B}$ Shine, ${ }^{1} \mathrm{~T}$ Makaya. ${ }^{1}$ Paediatric Endocrinology, Oxford University Hospitals NHS Trust, Oxford, UK; ${ }^{2}$ Health Education England, Thames Valley, Oxford, UK; ${ }^{3}$ Neonatology, Oxford University Hospitals NHS Trust, Oxford, UK; ${ }^{4}$ Biochemistry, Oxford University Hospitals NHS Trust, Oxford, UK

\subsection{6/archdischild-2020-rcpch.476}

Background Neonatal cortisol assessment is indicated in suspected adrenal insufficiency.

Aims/Objectives Review of neonatal cortisol assessment within our Trust over seven years, to analyse trends, indications, outcomes; and relationships between gestational age (GA), birth weight (BW) and cortisol assessment.
Methodology From cortisol results on neonates ( $\leq 30$ days age) between 2012-2018 (inclusive) we identified random/serial ('screening cortisols') versus cortisols done as part of Synathen tests.

We analysed trends for testing. Further data collection as follows:

- Screening cortisols: Indication, number of tests, outcomes.

- Synacthen tests: Indication, type of test [short Synacthen test (SST) vs low dose Synacthen test (LDST)], results, short/long term outcomes, relationship to BW/GA.

Results There were 412 cortisol tests over the 7 years, in 172 patients (table 1). Numbers were stable between 2012-2014, but between 2015/2016 and 2017/2018 there was a 230\% increase in cortisol; and $430 \%$ rise in Syacnthen tests. This was despite stable admission rates: 1997 patients over 2015/ 2016 and 1916 in 2017/2018.

Abstract G558(P) Table 1 Screening cortisol versus Synacthen tests

\begin{tabular}{|c|c|c|}
\hline & Screening cortisols & Synacthen tests \\
\hline $\begin{array}{l}\text { Number of } \\
\text { patients }\end{array}$ & $143(=83 \%)$ & $29(=17 \%)$ \\
\hline Split & $\begin{array}{l}66.4 \% \text { ( } n=95 / 143): \text { Single } \\
\text { screening cortisol test. } \\
33.6 \% \text { ( } n=48 / 143 \text { ): } 2 \text { or more } \\
\text { screening cortisol tests. }\end{array}$ & $\begin{array}{l}72.4 \%(n=21 / 29) \text { were SSTs. } \\
27.6 \%(n=8 / 29) \text { were LDSTs. }\end{array}$ \\
\hline $\begin{array}{l}\text { Top } 3 \\
\text { indications: }\end{array}$ & $\begin{array}{l}\text { Hypoglycaemia(35.6\%), } \\
\text { ambiguous genitalia(16\%), } \\
\text { conjugated jaundice(9\%). }\end{array}$ & $\begin{array}{l}\text { Hypoglycaemia(44.8\%), ambiguous } \\
\text { genitalia(6.9\%) and hyponatremia } \\
(6.9 \%) \text {. }\end{array}$ \\
\hline Outcomes: & $\begin{array}{l}\text { Only ONE patient was started on } \\
\text { treatment based on just } \\
\text { screening results. }\end{array}$ & $\begin{array}{l}38 \% \text { of the initial Synacthen tests were } \\
\text { abnormal }(n=11 / 29) \text {. } \\
\text { Of these } 28 \%(n=3 / 11) \text { remained on } \\
\text { treatment after age of } 2 \text { years: } 2 \\
\text { hypopituarism } 1 \text { primary adrenal } \\
\text { insufficiency }\end{array}$ \\
\hline
\end{tabular}

There was no significant relationship between premature versus term deliveries and abnormal Synacthen tests $(p=0.32)$; or between BW (i.e. SGA vs AGA) and abnormal Synacthen tests $(p=0.32)$.

Summary/Conclusions Exponential increase in cortisol assessments keeping in with the change in neonatal hypoglycemia guideline. Only $6 \%$ of those screened had initial suboptimal synacthen test. Subsequent reassessment of adrenal function is imperative as $72 \%$ of the initial abnormal synacthen results were transient. Less than $2 \%$ of all screened have on going adrenal insufficiency. There was no association between BW or GA and abnormal Syancthen result.

\section{G559(P) FAMILY ORIENTED VARIABLE AND ITS IMPACT ON CLINICAL PRACTICE}

${ }^{1} V$ Saxena, ${ }^{1} \mathrm{M}$ Tammali, 'S Mittal, ${ }^{2} \mathrm{~K}$ Jain. ${ }^{1}$ Neonatal Medicine, Leicester Royal Infirmary, Leicester, UK; ${ }^{2}$ Paediatric Respiratory, Leicester Royal Infirmary, Leicester, UK

\subsection{6/archdischild-2020-rcpch.477}

Aim To assess the clinical, parental involvement and economic impact of the weaning methods of oxyen in LTOT. 
Methodology Retrospective review of clinical records of babies discharged between Jan 2014 and Dec 2015 were compared to babies discharged between Jan 2016 to Dec 2017.

Old protocol, weaning done in increments of $30 \mathrm{~min}, 1 \mathrm{hr}$, $2 \mathrm{hr}, 3 \mathrm{hr}$ twice daily off, $6 \mathrm{hr}, 8 \mathrm{hr}, 10 \mathrm{hr}$ off with an OOS at each step. New protocol, general health and nutritional status guide the daytime $\mathrm{O}_{2}$ weaning. Weaning done in increments of $30 \mathrm{~min}, 2 \mathrm{hr}$ twice daily off, $6 \mathrm{hr}$ and $12 \mathrm{hr}$ off in day time followed 2-3 weeks later by two OOS, one in oxygen and one in air.

Results 33 babies were discharged each year on LTOT. Groups were comparable in mean birth weight $(\mathrm{kg})$, gestational age and comorbidities (table 1). New protocol was associated with shorter duration of $\mathrm{O}_{2}$ therapy (P value 0.005). There was saving of $£ 3215.54$ for cost of oxygen in 2016-17. The parent satisfaction and the Friends and Family test score were $100 \%$.

\begin{tabular}{llll} 
Abstract G559(P) Table 1 & & \\
\hline & $\begin{array}{l}2014-2015 \\
\text { Mean (95\% CI) }\end{array}$ & $\begin{array}{l}2016-2017 \\
\text { Mean }(95 \% \mathrm{Cl})\end{array}$ & $\begin{array}{l}\text { P } \\
\text { value }\end{array}$ \\
\hline Gender ratio (M: F) & $13: 18$ & $16: 13$ & 0.350 \\
Birth weight Kg & $906.2(812.0-1000.4)$ & $822.9(720.0-925.8)$ & 0.226 \\
Gestational age(weeks) & $26.7(25.8-27.7)$ & $25.9(25.0-26.7)$ & 0.141 \\
comorbidity- PDA & $77 \%$ & $93 \%$ & 0.089 \\
comorbidity NEC & $48 \%$ & $44 \%$ & 0.782 \\
duration of LTOT & $499.3(360.0-638.5)$ & $280.8(232.4-329.2)$ & 0.005 \\
(days) & & & \\
No. of oximetry studies (OSS) & $13.6(10.5-16.6)$ & $15.4(12.6-18.3)$ & 0.364 \\
No. of outreach visits & $15.5(13.4-17.6)$ & $16.3(14.3-18.3)$ & 0.593 \\
No. of clinic visits & $6.5(5.4-7.5)$ & $5.2(4.3-6.0)$ & 0.056 \\
O2 cylinder cost per one patient & $291.59(230.24-$ & $200.82(176.40-$ & 0.008 \\
$\mathrm{f}$ & $352.94)$ & $225.24)$ & \\
\hline
\end{tabular}

Conclusions Structured monitoring and weaning based on clinical parameters and parental input led to shorter duration of LTOT The service users' feedback was $100 \%$ positive. Not all activities to provide this service were coded.

\section{G560(P) SAFETY OF THE KAISER PERMANENTE EARLY ONSET NEONATAL SEPSIS RISK CALCULATOR: A MULTI CENTRE RETROSPECTIVE STUDY}

${ }^{1} \mathrm{KJ}$ Pettinger, ${ }^{2} \mathrm{C}$ Breidenbach-Roe, ${ }^{2} \mathrm{KJ}$ Mayers, ${ }^{3} \mathrm{~T}$ Pettinger, ${ }^{4} \mathrm{~B}$ Phillips, ${ }^{2} \mathrm{~L}$ McKechnie. ${ }^{1}$ Neonatal unit, Bradford Teaching Hospitals NHS Foundation Trust, Bradford, UK; ${ }^{2}$ Neonatal unit, Leeds Teaching Hospitals Trust, Leeds, UK; ${ }^{3}$ Department of Obstetrics and Gynaecology, Leeds Teaching Hospitals Trust, Leeds, UK; ${ }^{4}$ Centre for Reviews and Dissemination, University of York, York, UK

\subsection{6/archdischild-2020-rcpch.478}

Aims Early onset neonatal sepsis (EOS) is a rare but significant cause of mortality and morbidity. Babies are treated based on risk factors and clinical indicators, according to National Institute for Health and Care Excellence (NICE) guidelines.

An electronic risk calculator has been developed by Kaiser Permanente, providing an estimation of EOS risk for babies $\geq 34$ weeks gestation. Blood cultures are recommended if the risk is $\geq 1 / 1000$ live births, plus empirical antibiotics if $\geq 3$ / 1000. The baby can be categorised as Well/Equivocal/Ill and a 'risk after clinical exam' score given.

We evaluated a large number of EOS cases to determine if it would be safe to introduce the calculator locally.

Methods A list of positive blood cultures from babies $\geq 34$ weeks gestation was obtained from two tertiary neonatal units. Study periods were December 2016-November 2017 and July 2016-July 2018 in the first and second trusts respectively.

The necessary data for the calculator was obtained from maternal and infant records, and the calculator score recorded. For babies treated based on 'risk factors' as per NICE, the score at birth was used. For babies treated according to clinical features, the score after examination was used.

The primary outcome was whether the calculator would have recommended empirical treatment in babies who went on to have EOS.

Following consultation with the research and development department, there was no requirement for ethical approval.

Results There were 21,242 births in the study period and 24 cases of culture-proven EOS. 3 babies were commenced on antibiotics outside of NICE guidance. 11 babies were commenced on antibiotics due to risk factors for EOS; 13 due to clinical indicators.

Of the 24 babies with culture-proven EOS, empirical antibiotics were only recommended by the calculator in seven.

Of the 11 babies commenced on antibiotics due to risk factors, 10 would have had delayed or missed treatment if the calculator had been used.

Conclusion Whilst the calculator has resulted in a substantial reduction in antibiotic use in published studies, we have demonstrated that a large proportion of EOS cases may be missed by the calculator. Currently, the benefit of introducing the calculator does not outweigh the risks.

\section{G561(P) SENSITIVITY OF THE KAISER PERMANENTE EARLY- ONSET SEPSIS CALCULATOR: A SYSTEMATIC REVIEW AND META-ANALYSIS}

${ }^{1} \mathrm{KJ}$ Pettinger, ${ }^{2} \mathrm{KJ}$ Mayers, ${ }^{2} \mathrm{~L}$ McKechnie, ${ }^{3} \mathrm{~B}$ Phillips. ${ }^{1}$ Neonatal Unit, Bradford Royal Infirmary, Bradford, UKi ${ }^{2}$ Neonatal Unit, Leeds Teaching Hospitals Trust, Bradford, UK; ${ }^{3}$ Centre for Reviews and Dissemination, University of York, Heslington, UK

\subsection{6/archdischild-2020-rcpch.479}

Aims Determining which babies should receive antibiotics for possible early onset sepsis (EOS) is challenging. Kaiser Permanente have developed an electronic calculator providing an individualised estimation of EOS risk.

We performed a meta-analysis quantifying how many culture positive EOS cases might be 'missed' using the calculator, in addition to cases missed using National Institute for Health and Care Excellence (NICE) guidelines (CG149 2012).

Methods A systematic literature search using a modified cluster technique, snowballing from studies citing the article in which the calculator was widely publicised (Kuzniewicz 2017) on Ovid MEDLINE, Embase, Maternity \& Infant Care Database and Google scholar. Reference lists were reviewed.

Studies were eligible if they presented data evaluating the calculator, either by retrospective case review or prospective cohort study and identified at least one episode of EOS. 